\title{
Comparative Study between Bupivacaine Alone and With Dexamethasone as An Adjuvant in Ultrasound-Guided Popliteal Nerve Block in below Knee Surgeries
}

\section{Ahmed Alsaied Abd Elrahman ${ }^{1}$, Ayman Mohamady Eldemrdash²,}

Amir Abouzkry Elsayed ${ }^{2}$, Mohammed Hamdi Abolwafa Esmail*2

${ }^{1}$ Department of Anesthesiology, Intensive Care and Pain medicine, Faculty of Medicine, Sohag

University, ${ }^{2}$ Department of Anesthesiology, Intensive Care and Pain medicine, Faculty of Medicine, Aswan University

*Corresponding author: Mohammed Hamdi Abolwafa Esmail, Mobile: (+20) 01003057949, E-Mail: hamdi.anaest@gmail.com

\begin{abstract}
Background: The popliteal nerve block is a form of regional anesthesia utilized for a variety of foot and ankle conditions. This form of anesthesia has become a popular technique to decrease postoperative pain, decrease narcotic use, and increase patient satisfaction.

Objective: To compare the effect of adding dexamethasone to bupivacaine on duration of sensory and motor blockade of the popliteal sciatic nerve block in below knee surgeries.

Patients and Methods: This prospective, randomized, double blinded, control clinical trial was carried out in Aswan University Hospitals for one year on 50 adult patients undergoing surgeries below knee from January 2019 to December 2019. Results: There was no statistically significant difference between the two study groups regarding onset of both sensory and motor blocks, but the durations of both sensory and motor blocks were statistically significantly longer in group A than group B ( $\mathrm{P}=0.001$, both). In group A , all the 25 patients $(100 \%)$ requested their first analgesia through the first 12 hrs postoperatively, While in group B 11 patients (44\%) requested their first analgesia through the first 12 hrs postoperatively and 14 patients (56\%) requested their first analgesia through the second $12 \mathrm{hrs}$ postoperatively, with statistically significant difference between the 2 study groups $(\mathrm{P}=0.001)$. As regard total rescue analgesic dose given (Nalbuphine IV) it was statistically significantly lower in group A than in group $\mathrm{B}(\mathrm{P}=0.001)$.

Conclusion: Addition of dexamethasone to bupivacaine in ultrasound-guided popliteal block significantly prolonged the duration of postoperative sensory and motor block.
\end{abstract}

Keywords: Bupivacaine, Dexamethasone, Ultrasound-guided, Popliteal nerve block, Knee.

\section{INTRODUCTION}

Anesthesia for below-knee surgeries can be provided by general or loco-regional anesthesia and given the peripheral site of surgery, a combination of both is generally well-tolerated. Regional anesthesia confers excellent analgesia postoperatively, reducing the requirements for systemic analgesics. Anesthetic techniques are usefully divided into those appropriate for surgery to the foot and those for surgery to the ankle (1). Peripheral nerve blocks (PNBs) have been delivered via either single injection or continuous catheter infusion approaches. The single injection nerve block is easier to perform and requires less resources in follow up management, which is more cost-effective in our clinical practice ${ }^{(2)}$.

The role of ultrasound in performing nerve block is increasing over the more traditional technique of peripheral nerve stimulator. Compared to neurostimulation, ultrasound has been shown to improve the success rate and to reduce the block performance time ${ }^{(3)}$.

While the popliteal nerve block is principally used as a form of postoperative analgesia, it can be employed for fracture and dislocation reduction, exploration of foreign bodies, bedside incision and drainage procedures, and wound debridements. This can be beneficial in medically compromised patients. Profound analgesia during both the operative and postoperative time periods and the avoidance of systemic complications such as nausea and vomiting are also potential benefits of the popliteal nerve block. Other advantages include earlier discharge from the post-anesthesia care unit and decreased opioid consumption perioperatively ${ }^{(4)}$.

However, solitary nerve block is limited by the duration of effective analgesia coverage. The available choice of local anesthetics (LA) and maximum toxic dosage preclude the amount of local anesthetic that can be used with single injection. Finding adjuvants to the local anesthetic that could effectively and reliably extend the analgesia duration was the focus of researchers' efforts ${ }^{(5)}$.

One promising adjuvant is dexamethasone. Dexamethasone is a synthetic glucocorticoid drug with potent anti-inflammatory and immunosuppressant effects. Several studies have reported that $8-10 \mathrm{mg}$ of perineural dexamethasone can significantly prolong the analgesia duration of brachial plexus nerve block ${ }^{(6)}$. Two recent publications reported comparable effects on prolongation of analgesia duration between perineural and intravenously administered dexamethasone ${ }^{(7,8)}$, which lead to the assumption that the mechanism of dexamethasone as adjuvant in peripheral nerve block might be systemic in nature.

The objective of this study was to compare the effect of adding dexamethasone to bupivacaine on 
duration of sensory and motor blockade of the popliteal sciatic nerve block in below knee surgeries.

\section{PATIENTS AND METHODS}

This prospective, randomized double-blinded, comparative clinical trial was performed in Aswan University Hospital on 50 patients undergoing surgeries below knee. Randomization was computerized.

Sample size calculation: Using the OpenEpi, Version 3, open source calculator SS mean setting alpha errors at 5\%, confidence interval at $95 \%$, power at $90 \%$ and result from previous study Vermeylen et al. ${ }^{(9)}$ who compared dexamethasone and clonidine as adjuvants to a ropivacaine sciatic popliteal block for foot surgery. Compared to duration to first pain sensation in saline group (Mean \pm SD: $22 \pm 6$ hours), which was prolonged by 9 hours in dexamethasone group (Mean \pm SD: $31 \pm 9$ hours), therefore 21 patients were minimally needed in each group for this study. We studied on 25 patients in each group.

\section{Patients were allocated into 2 groups:}

Group $A$ (25 patients): received $2 \mathrm{ml}$ of dexamethasone $(8 \mathrm{mg})$ added to $28 \mathrm{ml} 0.5 \%$ bupivacaine (20 $\mathrm{ml}$ for sciatic nerve block and $10 \mathrm{ml}$ for saphenous nerve block).

Group B (25 patients): received $2 \mathrm{ml}$ of normal saline added to $28 \mathrm{ml} 0.5 \%$ bupivacaine without dexamethasone (20 $\mathrm{ml}$ for sciatic nerve block and $10 \mathrm{ml}$ for saphenous nerve block).

Inclusion criteria: Age: between 20 and 75 years. Patients scheduled for below knee surgeries, with American Society of Anesthesiologists (ASA) physical status I to III. Both genders.

Exclusion criteria: Patient refusal. Inability to consent and cooperate. Allergy to trial medication. Daily use of glucocorticoids as well as chronic pain.

\section{Technique:}

- Done while the patient was awake, in prone position. A high frequency linear ultrasound probe is used, the probe was positioned in the popliteal fossa with a short axis view of the sciatic nerve and popliteal vessels. The sciatic nerve bifurcation was identified, and the needle insertion point was marked on the skin just distal to the sciatic nerve bifurcation. The anticipated needle insertion area was swabbed with $0.5 \%$ chlorhexidine in $82 \%$ ethanol and the needle was inserted in-plane from the lateral end of the probe penetrating the biceps femoris muscle followed by injection of a total of $20 \mathrm{ml}$ of the mixture of local anesthetic with or without dexamethasone according to the group. The injection was visualized to confirm complete spread around the tibial and common peroneal nerves.

- All patients received a subsartorial single injection saphenous nerve block along with a single injection popliteal sciatic nerve block.

- Saphenous nerve block was carried out with the patient supine, the probe was placed transversely a few centimetres proximal to the apex of the femoral triangle (Scarpa's triangle) at the mid-thigh level assessed ultrasonographically. The saphenous nerve was visualized anterolateral to the femoral artery as a rounded, slightly hyperechoic structure. The skin was swabbed with $0.5 \%$ chlorhexidine in $82 \%$ ethanol, and a block needle $(80 \mathrm{~mm} 22 \mathrm{G})$ was advanced in plane from the lateral end of the probe penetrating the sartorius muscle. $10 \mathrm{ml}$ of the mixture of local anesthetic with or without dexamethasone according to the group.

\section{Patient evaluation and measurements:}

- The patients were assessed according to American Society of Anesthesiologists (ASA) classification of physical status.

- Airway was assessed according to Mallampatti classifications.

- An intravenous line was obtained for every patient.

- Patients were monitored with electrocardiography, pulse oximetry and noninvasive blood pressure monitoring.

- Postoperative follow up was carried out in the recovery and postoperative ward for 24 hours.

- The duration of analgesia was noted according to (0-10) visual analogue scale (VAS) for pain at every hour till the first 6 hours , 2-hourly till 12 hours, then 4-hourly till 24 hrs.

- Vas score 0 and 10 was taken as no pain and worst pain perceived respectively. The duration of analgesia was determined from the start of block till the existence of good analgesia. When the patient begins to experience the worst pain (VAS $\geq 4$ ).

- Rescue of analgesia was in the form of intravenous nalbuphine according to the severity of pain.

- The duration of motor block postoperatively was assessed every hour till the first 6 hours, 2-hourly till 12 hours, then 4-hourly till 24 hours, by examining each nerve individually.

\section{The followings were measured:}

I- Duration of Surgery: Time required for the surgical procedure was assessed in hours.

II- Onset of sensory block: After injection of the solution (time zero) every patient was checked in the following times: $0,5,10,15,20,30,60$ and 80 minutes for onset of sensory blockade using pinprick test using the following scale (three-point scale): (i) 0 points $=$ pinprick perceived as painful (normal sensation). (ii) 1 point $=$ analgesia to pinprick (blunted sensation). (iii) 2 
points $=$ anesthesia to pinprick (no perception). It was evaluated in the distributions of branches of sciatic and saphenous nerves; the posterolateral and anterolateral sides of the leg, and the plantar surface of the foot for the tibial nerve, the lateral leg and the dorsal surface of the foot for the common fibular nerve, and the anterior and medial surface of the leg for the saphenous nerve by the pinprick method with an 18- gauge, long bevel needle.

III- Onset of motor block: Assessed by plantar flexion and dorsiflexion of the ankle and toes. After injection of the total dose of LA (time zero) every patient was checked in the following times $0,5,10,15,20,30,60$ and 80 minutes for onset of motor blockade using the following scale: (i) 0 points $=$ no paresis. (ii) 1 point $=$ paresis. (iii) 2 points $=$ complete paralysis.

IV- Success rate: means complete sensory and motor block. Duration of sensory block (hours): It's the time from sensory block onset to time of restoration of sensation at the surgical site. Duration of motor block (hours): It's the time from motor block onset to restoration of global mobility in the foot and ankle.

V-Complications: we checked for development of complications like, hematoma, persistent neuropathic pain or symptoms and signs of local anesthetic toxicity and side effects related to systemic use of opioids.

VI- Visual analogue scale (VAS) for first 24 hours: Pain intensity was assessed using VAS. The VAS is consisted of a straight, vertical $10-\mathrm{cm}$ line; the bottom point represented -no pain $\|=(0 \mathrm{~cm})$ and the top - the worst pain you could ever have $\|=(10 \mathrm{~cm})$. Patients were asked to make a horizontal mark across the line at the place that indicated the amount of their pain sensation. Measurement of the line in centimeters from the 0 point provided the score. Patients were asked to rate their pain intensity at 1, 2, 3, 4, 5, 6, 8, 10, 12, 16, 20 and 24 hours after the block.

VII- Time to first analgesic request (Hr.): It was recorded from the time of block administration to the patient's first request for analgesic medication.

VIII- Total analgesic consumption in $\mathbf{2 4}$ hours: Total amount of supplemental analgesia (in $\mathrm{mg}$ ) required in the first 24 hours after operation was assessed by milligrams of nalbuphine required.

\section{Ethical approval and written informed consent:} An approval of the study was obtained from Aswan University Academic and Ethical Committee. Every patient signed an informed written consent for acceptance of the operation.

\section{Statistical analysis}

Recorded data were analyzed using the statistical package for social sciences, version 20.0 (SPSS Inc., Chicago, Illinois, USA). Quantitative data were expressed as mean \pm standard deviation (SD). Qualitative data were expressed as frequency and percentage. Independentsamples t-test of significance was used when comparing between two means. Chi-square $\left(\mathrm{x}^{2}\right)$ test of significance was used in order to compare proportions between two qualitative parameters. The confidence interval was set to $95 \%$ and the margin of error accepted was set to $5 \%$. P-value was considered significant at $<0.05$.

\section{RESULTS}

There was no statistically significant difference between the two study groups regarding age, gender, weight or duration of surgery (Table 1).

Table (1): Demographic data of the two study groups

\begin{tabular}{|l|l|c|c|l|}
\hline \multicolumn{2}{|c|}{ Demographic variable } & \multicolumn{1}{|c|}{$\begin{array}{c}\text { Group A } \\
(\mathbf{n = 2 5})\end{array}$} & $\begin{array}{c}\text { Group B } \\
(\mathbf{n = 2 5})\end{array}$ & -value \\
\hline \multirow{2}{*}{ Age } & Mean \pm SD & $37.9 \pm 12.3$ & $37.4 \pm 14.6$ & 0.909 \\
\hline \multirow{2}{*}{ Gender } & Male & 15 & 16 & \multirow{2}{*}{1.000} \\
\cline { 2 - 5 } & Female & 10 & 9 & \\
\hline \multirow{2}{*}{ Weight } & Mean \pm SD & $88.2 \pm 5.4$ & $89.3 \pm 6.4$ & 0.507 \\
\hline Duration of surgery $(\mathbf{h r s})$ & Mean \pm SD & $2.2 \pm 0.6$ & $2.2 \pm 0.6$ & 0.825 \\
\hline
\end{tabular}

There was no statistically significant difference between the two study groups regarding onset of both sensory and motor blocks, but the durations of both sensory and motor blocks were statistically significantly longer in group A than group B (Table 2). 
Table (2): Sensorimotor block evaluation data of the two study groups

\begin{tabular}{|l|l|l|c|c|c|c|}
\hline \multicolumn{3}{|c|}{ Item } & $\begin{array}{c}\text { Group A } \\
(\mathbf{n = 2 5})\end{array}$ & $\begin{array}{c}\text { Group B } \\
(\mathbf{n = 2 5})\end{array}$ & t & P-value \\
\hline $\begin{array}{l}\text { Onset } \\
(\text { min) }\end{array}$ & Sensory block & Mean \pm SD & $23.0 \pm 7.2$ & $22.6 \pm 7.5$ & 0.192 & 0.849 \\
\cline { 2 - 7 } & Motor block & Mean \pm SD & $24.2 \pm 6.6$ & $21.6 \pm 7.3$ & 1.322 & 0.192 \\
\hline $\begin{array}{l}\text { Duration } \\
\text { (hrs) }\end{array}$ & Sensory block & Mean \pm SD & $15.1 \pm 4.0$ & $8.2 \pm 2.1$ & 7.543 & $0.001^{*}$ \\
\cline { 2 - 7 } & Motor block & Mean \pm SD & $11.8 \pm 3.3$ & $5.7 \pm 1.4$ & 8.700 & $0.001^{*}$ \\
\hline
\end{tabular}

Group A: There was a highly significant increase in VAS all over the postoperative $24 \mathrm{hrs}$. In comparison with $1 \mathrm{hr}$ postoperatively there was a significant increase in the VAS started $8 \mathrm{hrs}$ postoperatively continued after $10 \mathrm{hrs}, 12$ hrs, $16 \mathrm{hrs}, 20 \mathrm{hrs}$ and $24 \mathrm{hrs}$ postoperatively.

Group B: There was a highly significant increase in VAS all over the postoperative $24 \mathrm{hrs,} \mathrm{In} \mathrm{comparison} \mathrm{with}$ $1 \mathrm{hr}$ postoperatively there was a significant increase in the VAS started $5 \mathrm{hrs}$ postoperatively, which continued after 6 hr, $8 \mathrm{hrs}, 10 \mathrm{hrs}, 12 \mathrm{hrs}, 16 \mathrm{hrs}, 20 \mathrm{hrs}$ and $24 \mathrm{hrs}$ postoperatively.

Between the two study groups: VAS was highly significantly higher in group B when compared with group A; started $3 \mathrm{hrs}$ postoperatively and continued after 4 hrs, 5 hrs, 6 hrs, 8 hrs, $10 \mathrm{hrs}, 12 \mathrm{hrs}$ postoperatively (Table 3 ).

Table (3): Comparison between the two studied groups according to VAS.

\begin{tabular}{|l|c|c|c|c|}
\hline VRS & $\begin{array}{c}\text { Group A } \\
(\mathbf{n = 2 5})\end{array}$ & $\begin{array}{c}\text { Group B } \\
(\mathbf{n = 2 5})\end{array}$ & $\mathbf{U}$ & P-value \\
\hline $\mathbf{1 ~ H r}$ & $0.0 \pm 0.0$ & $0.0 \pm 0.0$ & 312.5 & 1.000 \\
\hline $\mathbf{2 ~ H r}$ & $0.0 \pm 0.0$ & $0.0 \pm 0.0$ & 312.5 & 1.000 \\
\hline $\mathbf{3 ~ H R}$ & $0.0 \pm 0.0$ & $0.16 \pm 0.37$ & 262.5 & $0.039^{*}$ \\
\hline $\mathbf{4}$ HR & $0.0 \pm 0.0$ & $0.4 \pm 0.71$ & 225.0 & $0.005^{*}$ \\
\hline $\mathbf{5}$ HR & $0.0 \pm 0.0$ & $1.2 \pm 1.1^{\#}$ & 125.0 & $0.001^{*}$ \\
\hline $\mathbf{6 ~ H R}$ & $0.24 \pm 0.44$ & $2.4 \pm 1.5^{\#}$ & 39.5 & $0.001^{*}$ \\
\hline $\mathbf{8}$ HR & $0.96 \pm 0.79^{\#}$ & $2.4 \pm 1.4^{\#}$ & 131.5 & $0.001^{*}$ \\
\hline $\mathbf{1 0}$ HR & $2.1 \pm 1.1^{\#}$ & $3.0 \pm 1.2^{\#}$ & 181.5 & $0.009^{*}$ \\
\hline $\mathbf{1 2}$ HR & $2.7 \pm 1.6^{\#}$ & $3.8 \pm 2.0^{\#}$ & 193.5 & $0.018^{*}$ \\
\hline $\mathbf{1 6}$ HR & $2.8 \pm 1.5^{\#}$ & $2.6 \pm 1.2^{\#}$ & 298.5 & 0.780 \\
\hline $\mathbf{2 0}$ HR & $3.0 \pm 1.6^{\#}$ & $3.2 \pm 1.7^{\#}$ & 267.5 & 0.367 \\
\hline $\mathbf{2 4}$ HR & $3.9 \pm 1.3^{\#}$ & $3.7 \pm 2.2^{\#}$ & 280.5 & 0.529 \\
\hline F & 57.317 & 31.500 & & \\
\hline P-value & $0.001^{*}$ & $0.001^{*}$ & & \\
\hline
\end{tabular}

U: Mann-Whitney test. F: Repeated measures ANOVA test in each study group.

\#: Significant difference from $1 \mathrm{hr}$ postoperative value among each group individually using Bonferroni post-hoc test.

In group A, all the 25 patients (100\%) requested their first analgesia through the first $12 \mathrm{hrs}$ postoperative, while in group B 11 patients (44\%) requested their first analgesia through the first $12 \mathrm{hrs}$ postoperative and 14 patients $(56 \%)$ requested their first analgesia through the second $12 \mathrm{hrs}$ postoperatively, with statistically significant difference between the 2 study groups. As regarding total rescue analgesic dose given (Nalbuphine IV) it was statistically significantly lower in group A than in group B (Table 4).

Table (4): Evaluation data of analgesia rescue of the two study groups

\begin{tabular}{|c|c|c|c|c|}
\hline \multicolumn{2}{|c|}{ Rescue analgesia } & $\begin{array}{c}\text { Group A } \\
(n=25)\end{array}$ & $\begin{array}{c}\text { Group B } \\
(\mathbf{n}=25)\end{array}$ & P-value \\
\hline \multirow{7}{*}{ First request } & $6 \mathrm{HR}$ & 0 & 9 & \multirow{7}{*}{$0.001 *$} \\
\hline & $8 \mathrm{HR}$ & 0 & 7 & \\
\hline & $10 \mathrm{HR}$ & 3 & 6 & \\
\hline & $12 \mathrm{HR}$ & 8 & 3 & \\
\hline & $16 \mathrm{HR}$ & 9 & 0 & \\
\hline & $20 \mathrm{HR}$ & 3 & 0 & \\
\hline & 24 HR & 2 & 0 & \\
\hline \multirow{2}{*}{ Total analgesic dose in mg } & Mean \pm SD & $8.2 \pm 2.4$ & $11.0 \pm 2.9$ & \multirow{2}{*}{$0.001 *$} \\
\hline & Range & $5-10$ & $5-15$ & \\
\hline
\end{tabular}

Nausea was found in 2 patients in group A and 1 patient in group B, and vomiting in 1 patients in group A and 2 patients in group B with no statistically significant difference between the two study groups regarding complications (Table 5). 
Table (5): Complications among the two study groups.

\begin{tabular}{|c|c|c|c|}
\hline Complications & $\begin{array}{c}\text { Group A } \\
(\mathbf{n = 2 5})\end{array}$ & $\begin{array}{c}\text { Group B } \\
(\mathbf{n = 2 5})\end{array}$ & \multirow{2}{*}{ P-value } \\
\cline { 1 - 3 } Nausea & 1 & 1 & \multirow{2}{*}{0.759} \\
\hline Vomiting & 1 & 3 & \\
\hline
\end{tabular}

\section{DISCUSSION}

In our study with regard to the primary outcome of the effect on onset and duration of sensory and motor block, there was no statistically significant difference between the two study groups regarding onset of sensory and motor block, but the durations of both sensory and motor blocks were statistically significantly longer in group A than group B.

Similarly, Hauritz et al. ${ }^{(10)}$ who compared the postoperative duration of sensorimotor blockade with either dexamethasone or saline added to bupivacaineepinephrine had reported that addition of $8 \mathrm{mg}$ dexamethasone to $0.5 \%$ bupivacaine-epinephrine significantly prolongs the duration of sensorimotor popliteal sciatic nerve blockade, and reduces pain and opioid consumption in patients after major hind foot and ankle surgery, but there was no significant difference regarding of the effect on onset and duration of sensory and motor block.

Similarly, An et al. ${ }^{(11)}$ had reported that highdose perineural dexamethasone, but not systemic dexamethasone, combined with bupivacaine prolonged the duration of both sensory and motor block of mouse sciatic nerve.

By the same way, Kumar et al. ${ }^{(12)}$ showed in their study that dexamethasone addition significantly increases the duration of analgesia in patients receiving low volume supraclavicular brachial plexus block, although they reported that also the onset of sensory and motor block was significantly earlier in dexamethasone-receiving group compared to control group.

Regarding postoperative pain relief, our study showed that there was prolongation of duration of first analgesic requests in dexamethasone-receiving group. No significant side effects were seen in patients receiving dexamethasone as an adjunct. In agreement with the previously mentioned studies, the study of Zhang et al. ${ }^{(13)}$ who evaluated the analgesic efficacy of dexamethasone added to local anesthetics in ultrasound-guided transversus abdominis plane (TAP) block for the patients after abdominal surgery which revealed that dexamethasone added to local anesthetics in ultrasound-guided TAP block was a safe and effective strategy for postoperative analgesia in adult patients undergoing abdominal surgery.

In contrast to our study, Wegner et al. ${ }^{(14)}$ studied the effect of dexamethasone added to ropivacaine during TAP block for patients undergoing inguinal hernia repair or spermatocelectomy, and revealed that

they could not show a statistically significant prolongation of analgesia for TAP blocks with ropivacaine when dexamethasone was added.

In the present study there was no significant difference among the two groups as regard to demographic data (age, weight and sex).

Our results showed that the difference between the two groups regarding the onset of sensory block was statistically insignificant. As regard to the onset of motor block the difference between the two groups was also statistically insignificant.

Also we found that there was significant difference between the two groups regarding the duration of sensory and motor block with more prolongation in group A (dexamethasone group).

Our results showed that VAS was highly significantly higher in group B when compared with group A at $6 \mathrm{hrs}, 8 \mathrm{hrs}, 12 \mathrm{hrs}$ postoperatively.

The study showed that, all the 25 patients (100\%) in group A requested their first analgesia through the first $12 \mathrm{hrs}$ postoperatively. While in group B 11 patients (44\%) requested their first analgesia through the first $12 \mathrm{hrs}$ postoperative and 14 patients $(56 \%)$ requested their first analgesia through the second $12 \mathrm{hrs}$ postoperative with statistically significant difference between the 2 study groups.

Regarding total rescue analgesic dose given (Nalbuphine IV); it was statistically significantly lower in group $\mathrm{A}$ than in group $\mathrm{B}$.

With referral to the noticed inadvertent side effect; nausea was found in 1 patient in group A and 1 patient in group B and vomiting in 1 patient In group A and 3 patients in group $B$ with no statistically significant difference between the two study groups.

\section{CONCLUSION}

Addition of dexamethasone to bupivacaine in ultrasound-guided popliteal block significantly prolonged the duration of postoperative sensory and motor block.

\section{REFERENCES}

1. Wildsmith J, Armitage E, McClure J (2003): Principles and practice of regional anaesthesia. 3rd ed. London: Churchill Livingstone, Pp. 193-204. 
2. Merritt C, Mariano E, Kaye A et al. (2014): Peripheral nerve catheters and local anesthetic infiltration in perioperative analgesia. Best Practice and Research Clinical Anaesthesiology, 28: 41-57.

3. Cataldo R, Carassiti M, Costa F et al. (2012): Starting with ultrasonography decreases popliteal block performance time in inexperienced hands: aprospective randomized study. BMC Anesthesiology, 12:33-35.

4. Schipper O, Hunt K, Anderson R et al. (2017): Ankle block vs single-shot popliteal fossa block as primary anesthesia for forefoot operative procedures: 1191. -Prospective, randomized comparison. Foot Ankle Int., 38: 1188-1191.

5. Bailard N, Ortiz J, Flores R (2014): Additives to local anesthetics for peripheral nerve blocks: Evidence, limitations, and recommendations. American Journal of Health-System Pharmacy, 71: 373-385.

6. Parrington S, O'Donnell D, Chan V et al. (2010): Dexamethasone added to mepivacaine prolongs the duration of analgesia after supraclavicular brachial plexus blockade. Regional Anesthesia and Pain Medicine, 35: 422-426.

7. Fredrickson F, Danesh-Clough $T$, White $\mathbf{R}$ (2013): Adjuvant dexamethasone for bupivacaine sciatic and ankle blocks: results from 2 randomized placebo-controlled trials. Regional Anesthesia and Pain Medicine, 38: 300-307.

8. Rahangdale R, Kendall M, McCarthy $\mathrm{R}$ et al. (2014): The effects of perineural versus intravenous dexamethasone on sciatic nerve blockade outcomes: a randomized, double-blind, placebocontrolled study. Anesthesia and Analgesia, 118: 1113-1119.
9. Vermeylen K, De Puydt J, Engelen $\mathbf{S}$ et al. (2016): A double-blind randomized controlled trial comparing dexamethasone and clonidine as adjuvants to a ropivacaine sciatic popliteal block for foot surgery. Local Reg Anesth., 9:17-24.

10. Hauritz R, Hannig K, Henriksen C et al. (2017): The effect of perineural dexamethasone on duration of sciatic nerve blockade: a randomized, doubleblind study. Acta Anaesthesiol Scand., 62(4):548557.

11. An K, Elkassabany N, Liu J (2015): Dexamethasone as adjuvant to bupivacaine prolongs the duration of thermal antinociception and prevents bupivacaine-induced rebound hyperalgesia via regional mechanism in a mouse sciatic nerve block model. PLoS One, 10(4): e0123459.

12. Kumar A, Jitendre A, Bhanu C et al. (2016): Effect of dexamethasone in low volume supraclavicular brachial plexus block: A doubleblinded randomized clinical study. Journal of Anaesthesiology Clinical Pharmacology, 32: 234-7.

13. Zhang D, Zhou C, Wei D et al. (2019): Dexamethasone added to local anesthetics in ultrasound-guided transversus abdominis plain (TAP) block for analgesia after abdominal surgery: A systematic review and meta-analysis of randomized controlled trials. PLoS One, 14(1): e0209646.

14. Wegner R, Akwar D, Guzman-Reyes S et al. (2017): Evaluating the adjuvant effect of dexamethasone to ropivacaine in transversus abdominis plane block for inguinal hernia repair and spermatocelectomy: a randomized controlled trial. Pain Physician, 20:413-418. 